\title{
A Tentative Research on Learning Motivation for Non-English Majors under Multimedia Teaching Environment
}

\author{
Chunli LIU \\ City College, Wuhan University of Science and Technology, Wuhan, 430083, China \\ E-mail: 25467278@qq.com
}

Keywords: Learning Motivation; Non-English Majors; Multimedia Teaching Environment

\begin{abstract}
In this thesis, it mainly analyzes the non-English majors' motivational characteristics and intensity in Wuhan University of Science and Technology, the students' motivation changes after the experimental teaching, the multimedia teaching situation in Wuhan University of Science and Technology. After the teaching experiment under CALL teaching mode, the overall motivation of the experimental class were increased, while there was no significant change in the control class which taught by the traditional teaching mode.
\end{abstract}

\section{Introduction}

Motivation is always considered as an important factor in foreign language learning. The problem of motivation in foreign language learning is a well-focused topic, and many researches' results show that motivation plays a key role for foreign language learning success. Zhao Bing (2011) inquired the factors which aroused a decreased motivation for the non-English majors. The survey showed that the reasons were mainly the learners' English learning attitude, learning desire, classroom anxiety. [1]Huang Qiuwen (2011) found that there was a significant gender differences between non-English majors' motivational types and motivational intensity. Moreover, there is a significant correlation among the motivation, student's gender, and English language proficiency. Li Haiyan (2010) had explored the English learning characteristics of medical majors' motivation and their personal factors to motivation type in Inner Mongolia Medical University. [2]Jia Wei (2010) did a research and the result showed that the non-English majors in Xi Hua University generally got a clear orientation on English learning, but their overall English learning motivation is not strong enough, and there are some motivational strength differences among different genders, professional and English language proficiency. [3]Chen Yuhua (2009) survey the College students' learning motivation and the influence about different gender on learning motivation. As the widely use of computer-assisted language learning, what is the learner's motivation, especially for Non-English majors under this new teaching mode need a further study. [4] [5]From the learner's motivation and combined with the related motivational theories, this thesis has a questionnaire survey on the non-English majors' motivation under multimedia teaching background in Wuhan University of Science and Technology.

\section{Research Methodology}

A. Research questions

a. What are the features and intensity of non-English majors' English learning motivation in Wuhan University of Science and Technology?

b. What are the effective methods to intensify t non-English majors' English learning motivation in Wuhan University of Science and Technology?

B. Research subjects

The subjects in this study are 136 first-year non-English majors from Wuhan University of Science and Technology. 
Table 1 The basic information of the subjects

\begin{tabular}{|c|c|c|c|c|c|c|c|}
\hline & \multicolumn{2}{|c|}{ major } & \multicolumn{2}{c|}{ gender } & \multicolumn{3}{c|}{ Englishlevel } \\
\hline & EG & CG & male & female & under & CET-4 & CET-6 \\
\hline number & 68 & 68 & 60 & 76 & 25 & 70 & 41 \\
\hline$\%$ & 50 & 50 & 44 & 56 & 18 & 51 & 30 \\
\hline
\end{tabular}

(Note: $\mathrm{EG}=$ experimental group, $\mathrm{CG}=$ control group)

\section{Instruments}

The instruments to be adopted in the study are pre-test questionnaires, post-test and questionnaires. The pre-test questionnaire of learning motivation will be designed according to the questionnaire made by Qin Xiaoqing and Wen Qiufang (2002) and Gao Yihong (2003).

D. Date collection and analysis

The pre-test questionnaires were done among randomly selected 136 non-English majors in September 2014. In this study, 136 questionnaires were handed out, and 136 available questionnaires were collected, so the efficiency of this questionnaire is $100 \%$. To avoid some comprehensive misunderstanding, both of the pre-test questionnaires and the post-test questionnaires are written in Chinese. This dissertation uses the SPSS17.1 statistical software to analyze the collected data. The analysis includes reliability analysis, t-test, and descriptive analysis.

\section{Results Analysis and Discussion}

A. Results of the pre-test

a. The analysis of control group and experimental group in pre-test

Control group and experimental group in pre-test, the overall motivation and the individual factors of both groups will be analyzed. And next, the features and intensity of non-English majors' English learning motivation in Wuhan University of Science and Technology will be discussed.

Table 2 Descriptive analysis of EG and CG in pre-test

\begin{tabular}{|cc|c|c|c|c|}
\hline & & $\mathrm{N}$ & Mean & Std. Deviation & Std. Error Mean \\
\hline $\begin{array}{c}\text { general } \\
\text { motivation }\end{array}$ & $\mathrm{CG}$ & 68 & 2.9933 & .41937 & .05086 \\
& EG & 68 & 2.9125 & .40570 & .04920 \\
\hline
\end{tabular}

In Table 2, the descriptive analysis of the general motivation shows that, in control group, the Mean is 2.9933; while in the experimental group, the Mean is 2.9125. The results of the two data are basically the same.

b. The overall English learning motivation in control group and experimental group

Table 3 Descriptive analysis of the overall motivation in pre-test

\begin{tabular}{|c|c|c|c|c|c|}
\hline & $\mathrm{N}$ & Min & Max & Mean & Std.Deviation \\
\hline Language level & 136 & 1.88 & 4.13 & 2.9697 & .44966 \\
Leamer level & 136 & 1.44 & 3.94 & 2.9040 & .52252 \\
Leaming situation & 136 & 1.64 & 4.09 & 2.9592 & .49222 \\
Motivational behavior & 136 & 1.40 & 4.20 & 2.8809 & .58998 \\
Overall level & 136 & 1.79 & 3.88 & 2.9529 & .41306 \\
Valid N (list wise) & 136 & & & & \\
\hline
\end{tabular}

In Table 3, Descriptive analysis shows the overall level Mean of the student' motivation is 2.9529, with standard deviation of 0.41306. The result indicates that the participants responded with a low-medium degree of motivation in English learning. About these three parts of motivation, most participants have a low-medium motivation in language level (Mean=2.9697, SD=0.44966). The majority of the participants represent a low-medium motivation in learning situation (Mean=2.9592, $\mathrm{SD}=0.49222$ ) either. The learner level shows the lowest among these three parts of motivation (Mean=2.9040, SD=0.52252). Compared with the former three parts, the motivational behavior shows a lower mean score $($ Mean=2.8809, $\mathrm{SD}=0.58998)$. 
c. Analysis of the individual factors affecting on non-English majors' English learning motivation.

Table 4 The descriptive analysis of different English levels

\begin{tabular}{|c|c|c|c|c|c|c|c|c|c|}
\hline & \multirow[b]{2}{*}{$\mathrm{N}$} & \multirow[b]{2}{*}{ Mean } & \multirow{2}{*}{$\begin{array}{c}\text { S td .Devia } \\
\text { tion }\end{array}$} & \multirow{2}{*}{$\begin{array}{c}\text { S td . Enor } \\
\text { Mean }\end{array}$} & \multicolumn{2}{|c|}{$\begin{array}{c}95 \% \text { Confide nce } \\
\text { Internal of the } \\
\text { Differe nce }\end{array}$} & \multirow[b]{2}{*}{ Min } & \multirow[b]{2}{*}{ Max } \\
\hline & & & & & & Lower & Upper & & \\
\hline \multirow{3}{*}{$\begin{array}{l}\text { Inte mal } \\
\text { motivation }\end{array}$} & Groupl & 70 & $2 . \$ 21$ & 58160 & .06951 & 2.7435 & 3.0208 & 1.75 & 4.06 \\
\hline & Group2 & 40 & 2.9250 & .49094 & .07763 & $2.76 \$ 0$ & 3.0820 & 2.00 & 4.00 \\
\hline & Group 3 & 26 & 2.5962 & 61675 & .12096 & 2.3470 & 2.8453 & 1.50 & 3.75 \\
\hline \multirow{3}{*}{$\begin{array}{l}\text { External } \\
\text { motivation }\end{array}$} & Groupl & 70 & 3.2214 & 50638 & .06052 & 3.1007 & 3.3422 & 2.00 & 4.50 \\
\hline & Group2 & 40 & 2.9813 & 31718 & .05015 & 2.8798 & 3.0827 & 2.50 & 3.75 \\
\hline & Group 3 & 26 & 3.3269 & 36585 & .07175 & 3.1792 & 3.4747 & 2.75 & 4.00 \\
\hline \multirow{3}{*}{$\begin{array}{l}\text { Casual } \\
\text { attribution }\end{array}$} & Groupl & 70 & 2.8482 & 55081 & .06583 & 2.7169 & 2.9796 & 1.25 & $3.8 s$ \\
\hline & Group2 & 40 & 2.9375 & .48783 & .07713 & 2.7815 & 3.0035 & 1.88 & 3.88 \\
\hline & Group 3 & 26 & 2.9423 & 48892 & .09588 & 2.7448 & 3.1398 & 1.63 & 3.75 \\
\hline \multirow{3}{*}{$\begin{array}{l}\text { L anguage } \\
\text { arxie ty }\end{array}$} & Groupl & 70 & 3.1625 & 90856 & .14366 & 2.8719 & 3.4531 & 1.00 & 5.00 \\
\hline & Group2 & 40 & 2.9231 & 50383 & .09881 & 2.7196 & 3.1266 & 2.00 & 3.50 \\
\hline & Group 3 & 26 & 3.3071 & 91403 & .10925 & 3.0892 & 3.5251 & 1.00 & 5.00 \\
\hline \multirow{3}{*}{$\begin{array}{l}\text { Leaming } \\
\text { situation }\end{array}$} & Groupl & 70 & 2.2333 & 38450 & .04596 & 2.1417 & 2.3250 & 1.33 & 3.11 \\
\hline & Group2 & 40 & 2.2611 & 31382 & .04962 & 2.1607 & 2.3615 & 1.78 & 5.22 \\
\hline & Group 3 & 26 & 2.2179 & .43374 & .08506 & $2.042 \mathrm{~S}$ & 2.3931 & 1.22 & 3.11 \\
\hline \multirow[t]{3}{*}{ Self-efficacy } & Groupl & 70 & 2.7607 & .77253 & .09234 & 2.5765 & 2.9449 & 1.00 & 4 \\
\hline & Group2 & 40 & 2.9563 & .75083 & .11872 & 2.7161 & 3.1964 & 1.25 & 5.00 \\
\hline & Group 3 & 26 & 2.4808 & 64391 & .12628 & 2.2207 & 2.7408 & 1.00 & 4.00 \\
\hline \multirow{3}{*}{$\begin{array}{l}\text { Individual } \\
\text { need }\end{array}$} & Groupl & 70 & 3.1762 & 87866 & 10502 & 2.9667 & 3.3857 & 1.00 & 5.00 \\
\hline & Group2 & 40 & 3.2083 & 102861 & .16264 & 2.8794 & 3.5373 & 1.00 & 5.00 \\
\hline & Group 3 & 26 & 3.2436 & 68351 & .13405 & 2.9675 & 3.5197 & 2.00 & 5.00 \\
\hline \multirow{3}{*}{$\begin{array}{l}\text { Expec tancy- } \\
\text { value }\end{array}$} & Groupl & 70 & 3.1000 & .74988 & .08963 & 2.9212 & 3.2788 & 1.25 & 4.50 \\
\hline & Group2 & 40 & 3.1938 & 62401 & .09866 & 2.9942 & 3.3933 & 1.50 & 4.25 \\
\hline & Group 3 & 26 & 3.0192 & 56091 & 11000 & 2.7927 & $3.245 \mathrm{~s}$ & 1.75 & 4.25 \\
\hline \multirow{3}{*}{$\begin{array}{l}\text { Motivational } \\
\text { behavior }\end{array}$} & Groupl & 70 & $2 . \$ 557$ & .73189 & .08748 & 2.7112 & 3.0602 & 1.25 & 4.25 \\
\hline & Group2 & 40 & 3.1688 & 56723 & .08969 & 2.9873 & 3.3502 & 1.75 & 25 \\
\hline & Group 3 & 26 & 2.8173 & 38443 & .07539 & 2.6620 & 2.9726 & 2.00 & .50 \\
\hline
\end{tabular}

In Table 4, from the descriptive analysis on different English level, it is clear that, Group 2 has a higher internal motivation (Mean=2.9250, $S D=0.49049$ ) than the other groups. It means that the students who have passed the CET-6 have a higher an internal motivation. While in the external motivation, the mean score of Group 3 (Mean=3.3269, SD=0.36585) is higher than the other groups and Group 2 (Mean=2.9813, SD=0.31718) is the lowest. The result shows that the students who haven't passed any English level certificate are have a higher external motivation than the other groups. In the causal attribution, Group 3 (Mean= 2.9423, $S D=0.48892$ ) is a higher than the other groups. It shows that, these students have a relative clear idea about their failures in English learning. In language anxiety, Group 2 (Mean=2.9231, SD=0.50383) is the lowest than the other groups and Group 3 (Mean=3.3071, SD=0.91403) is the highest one. In learning situation, there are no significant differences among those three groups, Group 1 (Mean=2.2333, SD=0.38450), Group 2 (Mean=2.2611, SD=0.31382), Group 3 (Mean=2.2179, SD=0.43374). It means that, most students haven't felt any changes in their learning situation, so it is worthy to have a research that under the 
CALL environment and find out whether the students have changes in their learning motivation. In self-efficacy, Group 2 (Mean=2.9563, $S D=0.75083$ ) is higher than the other groups while Group 3 (Mean=2.4808, $\mathrm{SD}=0.64391$ ) is the lowest one. It means that, students who have passed the CET-6 are having a higher learning motivation. In the individual need, Group 3 (Mean=3.2436, $\mathrm{SD}=0.68351$ ) is the higher one while Group 1 (Mean=3.1762, SD=0.87866) is the lower one. It means that the students who haven't got any certificate are more likely to have English class in their studying. In expectancy-value, Group 2 (Mean=3.1938, SD=0.62401) is the higher one while the Group 3 (Mean=3.0192, SD=0.56091) is the lower one. It means that the students who have passed the CET-6 are more expectant in "When I finished my college studying, I will have a great progress”. In the motivational behavior, the lowest one is Group 3 while the highest one is Group 2. It means that students in Group 2 are more active to participate in some English activities than the other groups.

B. Results of the post-test

a. The analysis between control group and experimental group in pre-test and post-test

Table 5 Descriptive analysis of EG and CG between pre-test and post-test

\begin{tabular}{|cc|c|c|c|c|}
\hline & & Mean & N & Std. Deviation & Stcl. Error Mean \\
\hline \multirow{2}{*}{ Pair 1 } & CG-pre & 2.9933 & $6 \mathrm{~S}$ & .41937 & .05086 \\
& CG-post & 3.0032 & $6 \mathrm{~S}$ & .36216 & .04392 \\
& EG-pre & 2.9125 & $6 \mathrm{~S}$ & .40570 & .04920 \\
Pair 2 & EG-post & 3.1029 & $6 \mathrm{~S}$ & .35797 & .04341 \\
\hline
\end{tabular}

According to Table 5, the descriptive analysis of the pair 1 shows that, the mean score of the pre-test of control group is 2.9933, while that of the post-test of control group is 3.0032. There is no significant difference. The descriptive analysis of the pair 2 shows that, the pre-test of experimental group is Mean=2.9125, $\mathrm{SD}=0.4 .570$, while the post-test of experimental group is Mean=3.1029, $\mathrm{SD}=0.35797$, so it is obvious that there appears a promotion.

Table 6 Paired Samples T-test result of EG and CG between pre-test and post-test

\begin{tabular}{|c|c|c|c|c|c|c|c|c|c|}
\hline & & \multicolumn{5}{|c|}{ Paired Diffe re nces } & \multirow{3}{*}{$t$} & \multirow{3}{*}{ df } & \multirow{3}{*}{$\begin{array}{l}\text { S ig. (2 } \\
\text {-tailed) }\end{array}$} \\
\hline & & \multirow[b]{2}{*}{ Me an } & \multirow[b]{2}{*}{ S tol Deviation } & \multirow[b]{2}{*}{$\begin{array}{c}\text { S td. Enor } \\
\text { Mean }\end{array}$} & \multicolumn{2}{|c|}{$\begin{array}{l}95 \% \text { Confidence } \\
\text { Internal of the } \\
\text { Difference }\end{array}$} & & & \\
\hline & & & & & Lower & Upper & & & \\
\hline Pair 1 & $\begin{array}{l}\text { CG-pre - } \\
\text { CG-post }\end{array}$ & $-.009 \$$ & .54138 & .06565 & -.14085 & .12124 & -.149 & $6 S$ & .882 \\
\hline Pair 2 & $\begin{array}{l}\text { EG-pre - } \\
\text { EG-post }\end{array}$ & -.19048 & .53039 & .06432 & -.31886 & -.06209 & -2.961 & $6 S$ & .004 \\
\hline
\end{tabular}

(Note: $\mathrm{EG}=$ experimental group. $\mathrm{CG}=$ control group)

Table 6 clearly shows that in pair $1, \mathrm{P}=0.882>0.05$, which means there is no significant difference between the pre-test and the post-test of the control group, and it is not necessary to do a further discussion on it. While in pair $2, \mathrm{P}=0.004<0.05$, so there is an obvious significant difference between the pre-test and the post-test of experimental group. In other words, the research of teaching non-English majors in CALL mode has a positive result. Students' learning motivation has got a promotion under multimedia background.

b. The comparison from four motivational aspects 
Table 7 Descriptive analysis of EG between post -test and pre -test

\begin{tabular}{|c|c|c|c|c|c|}
\hline & & Mean & $\mathrm{N}$ & $\begin{array}{c}\text { Std. } \\
\text { Deviation }\end{array}$ & Std. Error Mean \\
\hline \multirow{2}{*}{ Pair 1} & Language L-post & 3.1987 & 68 & .79567 & .09649 \\
\hline & Language L-pie & 2.9357 & 68 & .49224 & .05969 \\
\hline \multirow{2}{*}{ Pair 2} & Leamer L-post & 3.2592 & 68 & .40824 & .04951 \\
\hline & Leamer L-pre & 2.9522 & 68 & .52604 & .06379 \\
\hline \multirow{2}{*}{ Pair 3} & Lea ning S-post & 3.1507 & 68 & .46828 & .05679 \\
\hline & Le arning S -pre & 2.9507 & 68 & .45711 & .05543 \\
\hline \multirow{2}{*}{ Pair 4} & Motivational B-post & 3.1434 & 68 & .42877 & .05200 \\
\hline & Motivational B-pre & $2.95 s 8$ & 68 & $.5 s 085$ & .07044 \\
\hline
\end{tabular}

In Table 7, Pair 1 shows that, language level in post-test (Mean= 3.1987, SD=0.79567) is higher than the language level in pre-test (Mean=2.0357, SD=0.49224). Pair 2 shows that, learner level in post-test (Mean=3.2592, $\mathrm{SD}=0.40824)$ is higher than learner level in pre-test (Mean= 2.9522, $\mathrm{SD}=$ 0.52604 ). Pair 3 shows that, learning situation in post-test (Mean $=3.1507, S D=0.46828$ ) is higher than the learning situation in pre-test (Mean= 2.9507, $S D=0.45711$ ). Pair 4 shows that, motivational behavior in post-test (Mean= 3.1434, $\mathrm{SD}=0.42877$ ) is higher than the motivational behavior in pre-test (Mean= 2.9588, $\mathrm{SD}=0.58085)$. These descriptions show that the students' learning motivation in experimental group has an overall promotion. From the data, it can be concluded that after taking the CALL teaching mode for more than two months, the experimental group has got a higher motivation than the control group who was taught by the traditional teaching method.

\section{Conclusion}

The non-English majors in Wuhan University of Science and Technology generally have a clear goal-orientation in English learning, and their major motivational type is instrumental motivation and learning situation motivation. But the overall English learning motivation is not strong. To intensify non-English majors' English learning motivation, we should take a full use of multimedia, increase their internal motivation, self-efficacy, motivational behavior, show a positive teacher's personality. For the further study, we should increase the learning contents, inspire the students themselves to choose what to learn and how to learn.

\section{Reference}

[1]Martin V. Covington,Kimberly J. Müeller. Intrinsic Versus Extrinsic Motivation: An Approach/Avoidance Reformulation[J]. Educational Psychology Review. 2001 (2)

[2] Paul R. Kleinginna,Anne M. Kleinginna. A categorized list of motivation definitions, with a suggestion for a consensual definition [J]. Motivation and Emotion. 1981 (3)

[3] Avi Kaplan,Martin L. Maehr. The Contributions and Prospects of Goal Orientation Theory[J]. Educational Psychology Review. 2007 (2)

[4] Helen W. Sullivan,Keilah A. Worth,Austin S. Baldwin,Alexander J. Rothman. The Effect of Approach and Avoidance Referents on Academic Outcomes: A Test of Competing Predictions [J]. Motivation and Emotion. 2006 (2)

[5] Barry R. Chiswick,Paul W. Miller. Immigrant earnings: Language skills, linguistic concentrations and the business cycle[J]. Journal of Population Economics. 2002 (1) 